April 2013

"The Welfare Value of FDA's Mercury-in-Fish Advisory: A Dynamic Reanalysis"

Christoph Rheinberger and James K. Hammitt 


\title{
The Welfare Value of FDA's Mercury-in-Fish Advisory: A Dynamic Reanalysis*
}

\author{
Christoph M. Rheinberger \\ Toulouse School of Economics and INRA
}

\author{
James K. Hammitt \\ Harvard University and INRA
}

April 5, 2013

\begin{abstract}
Assessing the welfare impact of consumer health advisories is a thorny task. Recently, Shimshack and Ward (2010) studied how U.S. households responded to FDA's 2001 mercury-in-fish advisory. They found that the average at-risk household reduced fish consumption by about $24 \%$, resulting in a $21 \%$-reduction in mercury exposure at the cost of a $28 \%$-reduction in cardioprotective omega-3 fatty acids. A rough assessment of the health costs and benefits led Shimshack and Ward to conclude that the advisory policy resulted in an overall consumer welfare loss. In this note, we propose a more comprehensive assessment that links the long term cardiovascular health effects of the advisory policy to life cycle consumption. In addition to mortality risk, our model values the loss in health quality from non-fatal cardiovascular diseases. Using the same dose-response relationships as Shimshack and Ward, we find that the expected health and mortality loss to the average at-risk household is much larger than they suggested. The analysis highlights the importance of accounting for dynamic effects when evaluating persistent changes in exposure to environmental health risks.
\end{abstract}

Keywords: Food safety, mercury, fatty acids, policy analysis, excess lifetime risk

JEL: I18, I38, P36, J17

\footnotetext{
* This work was sponsored by an INRA Scientific Package. CMR acknowledges additional funding from the Swiss National Science Foundation (grant no. PBEZP1-131130). JKH acknowledges support from the European Research Council (FP7/2007-2013, grant no. 230589). Corresponding author: CMR, Toulouse School of Economics (LERNA-INRA), 21 allée de Brienne, 31015 Toulouse, France; phone: +33-5-6163-5783; e-mail: crheinbe@toulouse.inra.fr.
} 


\section{Introduction}

Toxicologists use the term hormesis to refer to a substance that is beneficial at low doses but harmful at high doses. While the term describes properties of a single substance, it readily applies to other indivisible goods such as foods (Hammitt, 2004). Consider the example of dietary fish. Most fish are rich in omega-3 fatty acids, which have beneficial effects on cardiovascular health (Lee et al., 2009) and on the neurodevelopment of infants (Cohen et al., 2005a). Fish is also the primary source of human exposure to mercury (NRC, 2000), which is well known to harm the neurodevelopment of infants (Axelrad et al., 2007) and suspected to promote cardiovascular diseases in adults (Roman et al., 2011).

How healthy or harmful fish consumption is depends on the ingested doses of fatty acids and mercury. The consumption of moderate amounts of fish provides significant health benefits to both adults (Mozaffarian and Rimm, 2006) and infants (Oken et al., 2005). Yet consuming large amounts may be detrimental-especially for pregnant women and their unborn offspring (Axelrad et al., 2007). In 2001, the U.S. Food and Drug Administration (FDA) issued a mercuryin-fish advisory to better protect these target consumers. The advisory instructed households with pregnant women and young children to reduce fish consumption to no more than $12 \mathrm{oz}$ per week and to avoid consumption of some high-in-mercury fish species.

Recently, Shimshack and Ward (2010, hereafter SW) estimated the substitution effects that households made in response to FDA's mercury-in-fish advisory based on a consumer panel of nearly 15,000 U.S. households. They used their empirical estimates of the advisory-induced reduction in fish consumption to inform a prominent risk assessment model (Cohen et al., 2005b). Their tentative benefit-cost assessment suggests that the advisory resulted in a net harm to consumers as neurocognitive benefits to children were outweighed by their parents' larger risk of suffering a heart attack or stroke.

While we endorse SW's quasi-experimental approach, we believe that their policy assessment neglects three important points.

First, it estimates the effect of reducing fish consumption in adults for only one year. Hence, it overlooks the likelihood that women of child-bearing age and other household members who reduce fish consumption may continue to consume less fish for several years, perhaps for the rest of their lives. The cumulative effects of reducing fish consumption for several years rather than one is much larger (Rheinberger and Hammitt, 2012), especially if the reduction continues to older ages where the risk of cardiovascular diseases (CVD) increases rapidly.

Second, it ignores the disutility imposed by non-fatal cardiovascular events, albeit abundant empirical evidence suggests that people are willing to pay significant amounts of money to retain or improve their health (see Van Houtven et al., 2006 for a recent review).

Third, the monetary value or willingness-to-pay (WTP) for a persistent change in CVD risk depends crucially on the duration of the change and the ages over which it is experienced (Hammitt, 2007; Johansson, 2001).

A comprehensive evaluation of the FDA mercury-in-fish advisory warrants a life cycle assessment of the various health effects. Below, we adopt the life cycle consumption model of 
Murphy and Topel (2006, hereafter MT) to reevaluate the advisory. In a nutshell, our results indicate that for a short-term reduction in fish intake the welfare loss of increased CVD mortality is close to the loss estimate by SW. However, if the advisory induced people to reduce fish consumption for more than a year, health losses would be much larger. Moreover, the expected welfare loss associated with reduced quality of life after suffering a non-fatal CVD event is estimated to be comparable to the welfare loss associated with reduced life expectancy. We conclude that the overall welfare effect of the mercury-in-fish advisory is likely to be even less favorable than SW estimated.

In the remainder of this note, we first discuss how advisory-induced changes in fish consumption affect a consumer's risk profile. We then outline a tractable life cycle consumption model and derive the relevant health valuation metrics from this model. Using SW's empirical estimate of the reduction in fish consumption after the implementation of the advisory, we present welfare estimates for both fatal and non-fatal CVD risk increments. We close with some comments on the valuation of long-term changes in health risks.

\section{Consumer risk profiles}

At-risk households' consumption responses to FDA's 2001 mercury-in-fish advisory are clearly summarized in SW. In Figure 1, we provide a stylized model of how the reduction in fish intake affects the risk profile of a representative consumer.

Assume that the consumer eats the amount $Q_{0}$ of fish per year (Panel A). At age $a$, she takes notice of the advisory and, because she is or plans to become pregnant, she reduces fish intake from $Q_{0}$ to $Q_{1}$. The body concentrations of mercury and fatty acids fall within a few weeks from level $M_{0}$ to $M_{1}$ and from $P_{0}$ to $P_{1}$, respectively (Panel B). The risk of a neurocognitive deficit to her offspring decreases as a consequence of the reduced mercury exposure. This beneficial effect is partly offset by the reduced intake of fatty acids (unless the consumer takes fish oil supplements). ${ }^{1}$ At the same time, the consumer's risk of suffering an acute cardiovascular disease increases (Panels C and E) as the cardioprotective effect of fatty acids exceeds the cardiovascular risk of mercury on average, given the concentrations in dietary fish (Mozaffarian and Rimm, 2006).

The dietary change affects both life expectancy and life quality by shifting the survival curve from $S_{0}$ to $S_{1}$ (Panel D) and the life quality curve from $H_{0}$ to $H_{1}$ (Panel F). The size of these shifts hinges on the prevalence of acute cardiovascular diseases at all ages $t \geq a$, the quantity of fish consumed before and after the dietary change, and whether or not the consumer reverts to the preadvisory consumption level later in life.

Economic theory implies that the welfare effect of FDA's mercury-in-fish advisory can be assessed by comparing consumers' WTP to avoid increments in cardiovascular risk with the monetized benefits of reductions in mercury exposure of unborn children (Garber and Phelps, 1997). The change in mortality risk can be monetized by the consumers' WTP for risk

${ }^{1} \mathrm{SW}$ estimate the adverse effect of reduced fatty acid exposure offsets about two-thirds of the beneficial effect of reduced mercury exposure, see their Table 6 . 
reductions, accounting for the time pattern of the risk change (Hammitt, 2007). Similarly, increments in the lifetime risk of non-fatal CVDs events can be valued by monetizing the expected loss in life quality (Murphy and Topel, 2006).

Since family food choices usually affect all household members, changes in cardiovascular health risk must be aggregated across the members of at-risk households to assess the total health effect of the advisory-induced reduction in fish consumption. The sum of these monetized health risks can be compared with the monetary value of the effects on unborn children. For a household, the net effect depends on the ages over which the mother and other household members reduce fish consumption and the number of children born.

\section{Life cycle assessment of changes in cardiovascular risk}

MT's model builds on earlier life cycle models (Arthur, 1981; Cropper and Sussman, 1990; Rosen, 1988; Shepard and Zeckhauser, 1984; Yaari, 1965), all of which presume that a consumer of age $a$ seeks to maximize her remaining lifetime expected utility:

$$
\int_{a}^{\infty} H(t) u(c(t), l(t)) S(t, a) e^{-\rho(t-a)} d t,
$$

where $\rho$ is the consumer's rate of pure time preference. Age-dependent utility derived from consumption $c(t)$ and leisure time $l(t)$ is moderated by the quality of the consumer's health $H(t) \leq$ 1 at each age $t \geq a$, and the utility of death is normalized to zero (see Rosen, 1988).

Changes in mortality risk enter the model through the survivor function:

$S(t, a)=\exp \left[-\int_{a}^{t} \mu(\tau) d \tau\right]$

where $\mu(\tau)$ is the instantaneous mortality rate and $S(t, a)$ denotes the corresponding probability of surviving from age $a$ to at least $t$. A change in mortality affects the survivor function by:

$$
\Delta S(t, a) \approx S(t, a) \int_{a}^{t} \mu_{0}(\tau)-\mu_{1}(\tau) d \tau=S(t, a) \Gamma(t, a),
$$

with $\mu_{0}(\tau)$ and $\mu_{1}(\tau)$ denoting mortality rates before and after the policy intervention. ${ }^{2}$ This implies that the same health shock (i.e., absolute change in hazard) has a larger impact on life expectancy if it occurs earlier in life-no matter whether the shock is temporary or permanent (Johannesson et al., 1997).

Following Yaari (1965), MT assume a perfect capital market in which actuarially fair annuities are available so that the discounted value of future consumption equals expected wealth. (Cropper and Sussman (1990) extend the model to the case without access to fair annuities.) The consumer hence chooses $c(t)$ and $l(t)$ to maximize:

$$
\underset{c(t), l(t)}{\arg \max } U(a)=\int_{a}^{\infty}\left\{H(t) u(c(t), l(t)) e^{-\rho(t-a)}+\lambda[y(t)-c(t)] e^{-r(t-a)}\right\} S(t, a) d t+\lambda A(a),
$$

${ }^{2}$ Eq. (3) is a first-order approximation obtained by differentiating Eq. (2). 
where $y(t)$ denotes period-specific income, $\rho$ is the private rate of time preferences, $r$ is the market interest rate at which the consumer can borrow or lend, $A(a)$ are initial assets, $H(t)$ is exogenous, and $\lambda$ is the Lagrange multiplier.

The marginal rate of substitution between the risk of dying in the current year $\mu(a)$ and the current assets $A(a)$ measures the value per statistical life at age $a$ :

$V_{\mu}(a) \equiv-\frac{\partial U(a) / \partial \mu(a)}{\partial U(a) / \partial A(a)}=\frac{1}{\lambda} \int_{a}^{\infty} H(t) u(c(t), l(t)) e^{-\rho(t-a)}+\lambda[y(t)-c(t)] e^{-r(t-a)} S(t, a) d t$.

The first order condition of the maximization problem in Eq. (4) with respect to wealth is:

$$
\lambda=H(t) u_{c}^{\prime} e^{(r-\rho)(t-a)},
$$

By inserting Eq. (6) into Eq. (5), the notation can be further simplified to:

$V_{\mu}(a)=\int_{a}^{\infty} v(t) e^{-r(t-a)} S(t, a) d t$,

where $v(t)=u(c(t), l(t)) / u_{c}^{\prime}+y(t)-c(t)$ is an expression for the age-specific value of a statistical life year (Aldy and Viscusi, 2008). ${ }^{3}$

By the above formulation the value of remaining lifetime is independent of health quality. ${ }^{4}$ This is not to say that improvements in health are worthless, however. The marginal value of reducing the risk of a fall in $H(t)$, such as that following a non-fatal heart attack suffered at age $a$, is equal to:

$$
V_{\eta}(a) \equiv-\frac{\partial U(a) / \partial \eta(a)}{\partial U(a) / \partial A(a)}=\int_{a}^{\infty} \frac{u(c(t), l(t))}{u_{c}^{\prime}} e^{-r(t-a)} \underbrace{\frac{H_{\eta}^{\prime}(t)}{H(t)}}_{h(t)} S(t, a) d t .
$$

where $\eta(a)$ denotes the age-dependent health decay rate, and $h(t)$ is the expected relative change in health quality at any age $t \geq a$ caused by a change in the risk of a non-fatal health outcome. $V_{\mu}$ and $V_{\eta}$ are the welfare metrics we will use below to value changes in consumers' cardiovascular health as induced by the reduced fish consumption that $\mathrm{SW}$ found in their empirical analysis.

\section{Calibration}

We calibrated the life cycle consumption model assuming Gompertz hazard functions (Leung, 1994). In a first step, we fitted overall and cardiovascular mortality rates for the U.S. population (Table 1) based on current life tables (Arias, 2011) and death statistics (Heron et al., 2009). We then took the average reduction in fish consumption among target consumers, $\Delta Q$, as estimated by SW and converted it into changes in cardiovascular risk using the same dose-response functions as SW (Table 2). The dose-response function assumes that fish consumption affects the

\footnotetext{
${ }^{3}$ Here and below, primes indicate first derivatives with respect to the subscript.

${ }^{4}$ This follows because, under the utility function assumed in Eq. (1), both the utility gain from survival and the marginal utility cost of spending are proportional to $H(t)$ (Hammitt, 2002).
} 
relative risk of CVD; hence the change in absolute risk is proportional to baseline CVD risk, which increases with age. The mathematical details of this conversion are given in the Appendix.

We borrowed MT's values for $v(t), y(t), c(t)$, and $H(t)$ as summarized in Table 3 . Their estimates of $y(t)$ and $c(t)$ are based on official statistics on annual income and consumption expenditure; $v(t)$ and $H(t)$ are calibrated to $y(t)$ and $c(t)$ using the first-order condition (6) and imply a value per statistical life very similar to the one assumed by $\mathrm{SW} .5$

There are several ways to model the effect of a change in the risk of a non-fatal cardiovascular event on life quality. The approach proposed here builds on the idea that a stroke or heart attack at any age $t \geq a$ can be conceptualized as a random binary event to be survived with probability $\pi(t)$. This conditional survival probability can be approximated from age-specific incidence and mortality rates of CVD events (Table 1) and enables calculation of the odds of surviving a random CVD event. The associated increment in the risk of a non-fatal CVD event, $\Delta p(t)$, is obtained by multiplying the odds ratio and the advisory-induced increment in CVD mortality risk. ${ }^{6}$

A survived CVD event entails a loss in health quality, which we assume to be permanent and estimate based on Medical Expenditure Panel Survey (MEPS) data. ${ }^{7}$ The 2000-2003 waves of MEPS asked participants to rate their overall health quality using the EQ-5D metric (EuroQol Group, 1990). We regressed the health quality scores of 32,222 individuals aged 35 to 90 on their age, CVD status, and other controls that affect perceived health quality. ${ }^{8}$ About $7.5 \%$ of the sample had previously suffered a stroke or heart attack. Fig. 2 displays the reported and predicted health quality scores for individuals of different ages who had or had not ever suffered a non-fatal CVD event. The health quality scores predicted for individuals with and without CVD yield a relative measure of CVD-induced loss in health quality:

$$
\Delta q(t)=1-\mathrm{E}[\mathrm{Y}(t) \mid \mathrm{CVD}=1, \overline{\mathbf{X}}] / \mathrm{E}[\mathrm{Y}(t) \mid \mathrm{CVD}=0, \overline{\mathbf{X}}]
$$

where $\overline{\mathbf{X}}$ denotes the controls evaluated at sample means. Together, $\Delta q(t)$ and $\Delta p(t)$ define the advisory-induced change in the health decay rate: $\Delta q(t) \Delta p(t)=\Delta \eta(t)$. Once $\Delta \eta(t)$ is known, it is straightforward to derive the advisory-induced change in life quality, $\Lambda(t, a)=\int_{a}^{t} \Delta \eta(\tau) d \tau$. The relative effect of a change in non-fatal health risk on life quality can then be calculated as:

$$
h(t) \equiv \log H_{0}(t, a)-\log H_{1}(t, a)=\log \left[\left(1+\Lambda(t, a)^{-1}\right] .\right.
$$

5 This calibration seems appropriate for the comparative purpose of our note, but one could choose other values of $v(t), y(t), c(t)$, and $H(t)$.

${ }^{6}$ Formally, the risk of a non-fatal and a fatal CVD event are related through: $p(t)=\mu(t) \pi(t) /(1-$ $\pi(t)$ ), or equivalently: $\operatorname{Pr}($ Survive CVD $)=\operatorname{Pr}($ Death $\mid$ CVD occurs $) * \operatorname{Pr}($ CVD occurs $) * \operatorname{Pr}($ Survive CVD |CVD occurs) / Pr(Death |CVD occurs).

${ }^{7}$ MEPS data were retrieved from: http://meps.ahrq.gov/mepsweb.

${ }^{8}$ We included gender, race, body mass index, smoking status, depression status, angina status, diabetes status, income status, and medical expenditure in the past year as controls. Details are in the Appendix. 


\section{Results}

In Table 4 we report estimated monetary values of the decreased duration and quality of life among adult members of the average at-risk household expected from a $24 \%$ reduction in fish consumption (SW's central estimate). We consider reduced fish consumption over a period of one to ten years, assuming consumers return to their initial consumption level $Q_{0}$ once they pass childbearing age. Note that estimated CVD losses for consumers younger than 35 are assumed to be negligible, because their baseline risk is so small (Lloyd-Jones et al., 2010). We also provide estimates for a life-long reduction that could occur because eating habits persist.

Depending on the age at which fish consumption is reduced and the length of the dietary change, the expected monetized health loss to the average at-risk consumer varies from $\$ 0$ to $\$ 151$. Losses in life expectancy and in life quality contribute about equally to the overall health loss. Compared to SW's central loss estimate of $\$ 19$ for households who reduced but did not eliminate fish consumption (see their Table 6), our estimates become much larger as soon as the dietary change spans a period longer than a year. ${ }^{9}$ This is because the expected losses in life expectancy and life quality increase with each year of lower fish consumption at an increasing rate, as the baseline CVD risk increases with age. Since the proposed life cycle consumption model is based on a relative assessment of CVD risk, it is also not surprising that the expected health loss from reduced fish consumption increases with the switching age of consumers.

SW also estimated the share of consumers who stopped eating significant quantities of fish after receiving the mercury warning. They estimated that about $8.1 \%$ of U.S. consumers reduced their fish consumption to less than $100 \mathrm{~g}$ of fish per month, and that this would increase the risk of a heart attack by $17 \%$ and the risk of a stroke by $12 \%$. Exploiting the relative nature of the risk assessment within the life cycle consumption model, we can simply scale up the estimates reported in Table 4 by a factor of 4.2 to assess the health loss of ceasing fish consumption. ${ }^{10}$ Again, for dietary changes longer than a year the expected health loss to the average at-risk household is much larger than the $\$ 72$ obtained by SW.

\section{Conclusions}

Assessing the welfare impact of consumer health advisories is a thorny task. In this note, we combine SW's (2010) estimates of the causal effect of the advisory message on American households' fish consumption and MT's (2006) life cycle consumption model to reevaluate FDA's mercury-in-fish advisory. We find the adverse effects on adult health are likely to have

\footnotetext{
${ }^{9} \mathrm{SW}$ assumed that the average at-risk household consists of 1.92 adults (of the same age). In order to facilitate comparison with their reported estimates, one would have to multiply our estimates by a factor 1.92 .

${ }^{10}$ The scaling factor [4.2] can be calculated as: Share of ceasing consumers [8.1\%] * (Relative increment in heart attack risk [17\%] + Relative increment in stroke risk [12\%])/\{Average yearly fish consumption $[0.49 \mathrm{~kg} / \mathrm{yr}] *$ (dose-response function for heart attack risk [7.50 E-3 yr/kg] + dose-response function for stroke risk [3.85 E-3 yr $/ \mathrm{kg}])\}$.
} 
been substantially larger than assessed by SW, and hence the net welfare effects of the policy to be more adverse than they suggested.

The most important difference between our dynamic analysis and SW's original analysis is that we account for the likelihood that reductions in fish consumption last more than one year. SW analyzed the effects of reducing fish consumption for one year on the cognitive effects to offspring (assumed to persist over their lifetimes) and the incremental CVD risk from the same consumption change to adults. Realistically, women whose behavior is affected by the advisory may reduce fish consumption over the period during which they are or may become pregnant. After child-bearing, they may or may not revert to their previous fish consumption levels. Other household members, notably their spouses, may also reduce fish consumption over the same period. The assessment of the net welfare effects of the advisory on parents and offspring requires determining the number, ages, and periods over which adults reduce fish consumption, and the number of children born who benefit from reduced mercury exposure.

The effects of a multi-year reduction in fish consumption on CVD risk and the monetary value of the risk change could be assessed, to first order, by multiplying the effects of a one year change presented by SW. For dietary changes that last more than a few years, however, this approximation will be biased, for both CVD risk and valuation (Johansson, 2001). In particular, linear extrapolation will significantly understate the increment in CVD risk. This follows because lower fish consumption increases the relative risk of CVD and so the absolute risk increase is proportional to baseline risk, which rises with age. Hence total CVD risk is a convex function of the duration of the reduction in fish consumption.

The effect on monetary valuation of the risk change is less clear. Risk changes at older ages should be valued by an age-specific value per statistical life, which may decrease with age (Hammitt, 2007; Johansson, 2002), and should be discounted for latency. Our use of the MT (2006) model to value mortality risk implies that the age-specific value per statistical life decreases with age because of reduced life expectancy and future health. The value of a constant annual risk reduction is therefore a concave function of the number of years over which it is experienced. In the current application, the increasing risk change outweighs the decreasing valuation so that the monetary value of changes in CVD risk is a convex function of duration of the dietary change.

A second important difference between our analysis and SW's is that we include the value of reduced health quality associated with non-fatal CVD. While conceptually straightforward, including the value of morbidity effects appears to be quite important in this case. The estimated monetary value of the expected reduction in health quality is comparable to the value of reduced longevity, effectively doubling the loss if only mortality is included.

In sum, welfare assessment for persistent changes in factors that influence risk of fatality or chronic disease requires using a dynamic model to account for how changes in risk and valuation accumulate over the course of life. The value of a one year change in risk exposure (aka a "blip", Johannesson et al., 1997) substantially underestimates the value of a multi-year change. Although the value of a multi-year change can be approximated by extrapolating the effects of a short-term change in exposure, such an approach may yield significantly biased welfare estimates. 


\section{Tables}

Table 1: Hazard functions for overall, heart attack, and stroke mortality in the U.S. population.

\begin{tabular}{llll}
\hline Hazard functions $^{\mathrm{a}}$ & Shape parameter $[\alpha]$ & Scale parameter $[\beta]$ & Source \\
\hline Overall mortality rate $\left[\mu_{0}(t)\right]$ & $6.535 \mathrm{E}-5$ & $8.376 \mathrm{E}-2$ & (Arias, 2011) \\
Heart attack mortality rate $\left[\mu_{\mathrm{h}}(t)\right]$ & $3.395 \mathrm{E}-6$ & $9.272 \mathrm{E}-2$ & (Heron et al., 2009) \\
Stroke mortality rate $\left[\mu_{\mathrm{s}}(t)\right]$ & $1.166 \mathrm{E}-6$ & $1.050 \mathrm{E}-1$ & (Heron et al., 2009) \\
CVD incidence rate $[\iota(t)]$ & $3.045 \mathrm{E}-4$ & $6.406 \mathrm{E}-2$ & (Lloyd-Jones et al., 2010) \\
Survival of a CVD event $[\pi(t)]^{\mathrm{b}}$ & $2.242 \mathrm{E}-2$ & $3.176 \mathrm{E}-2$ & $1-\left[\mu_{\mathrm{s}}(t) / \iota(t)+\mu_{\mathrm{h}}(t) / \iota(t)\right]$ \\
\hline
\end{tabular}

Notes: ${ }^{\mathrm{a}}$ Gompertz hazard function of the form $\mu(t)=\alpha \exp (\beta t) ;{ }^{\mathrm{b}}$ Complementary hazard function of the form $\pi(t)=1-\alpha \exp (\beta t)$.

Table 2: Dose-response relationships.

\begin{tabular}{lll}
\hline Parameter & Value & Source \\
\hline Heart attack risk dose - response $\left[\psi_{\mathrm{h}}\right]$ & $7.500 \mathrm{E}-3$ per kg/yr & (Cohen et al., 2005b) \\
Stroke risk dose - response $\left[\psi_{\mathrm{s}}\right]$ & $3.846 \mathrm{E}-3$ per kg/yr & (Cohen et al., 2005b) \\
Reduced fish intake $[\Delta Q]^{\mathrm{a}}$ & $4.940 \mathrm{E}-1 \mathrm{~kg} / \mathrm{yr}$ & (Shimshack and Ward, 2010)
\end{tabular}

Notes: ${ }^{a}$ Calculation based on the product of the estimated proportional reduction $(21.1 \%)$ and the annual per capita fish consumption ( $2.334 \mathrm{~kg}=5.147$ pounds), see the Appendix of SW's paper.

Table 3: Calibration of MT's life cycle consumption model (Murphy and Topel, 2006).

\begin{tabular}{|c|c|}
\hline Component & Functional form \\
\hline Value of a statistical life year & $v(t)=-1.288 \mathrm{E}-9 t^{5}+4.384 \mathrm{E}-7 t^{4}-5.411 \mathrm{E}-5 t^{3}+2.862 \mathrm{E}-3 t^{2}-6.004 \mathrm{E}-2 t+0.63$ \\
\hline Life cycle income & $y(t)=\left\{\begin{array}{l}-1.236 \mathrm{E}-5 t^{4}+3.412 \mathrm{E}-3 t^{3}-3.489 \mathrm{E}-1 t^{2}+15.97 t-52.7, t<65 \\
-1.776 \mathrm{E}-6 t^{4}+2.841 \mathrm{E}-4 t^{3}+1.712 \mathrm{E}-2 t^{2}-5.205 t+286.8, t \geq 65\end{array}\right.$ \\
\hline Life cycle consumption & $c(t)=\left\{\begin{array}{l}3 \mathrm{E}-2 t^{4}+6.1 \mathrm{E}-3 t^{3}-3.914 \mathrm{E}-1 t^{2}+8.197 t-1.245 \mathrm{E} 5, t<65 \\
2.975 \mathrm{E}-2 t^{4}-10.310 t^{3}+1.352 \mathrm{E} 3 t^{2}-8.090 \mathrm{E} 3 t+1.932 \mathrm{E} 6, t \geq 65\end{array}\right.$ \\
\hline Life cycle health quality & $H(t)=\left\{\begin{array}{l}1, t<40 \\
7.983 \mathrm{E}-2+1.011 \exp \left[-\exp [19.014] t^{4.521}\right], t \geq 40\end{array}\right.$ \\
\hline
\end{tabular}


Table 4: Monetized losses of life expectancy and life quality among target consumers.

\begin{tabular}{|c|c|c|c|c|c|}
\hline \multirow[b]{2}{*}{ Starting age: } & \multicolumn{5}{|c|}{ Period of the dietary change: } \\
\hline & $1 y r$ & $2 y r s$ & $5 y r s$ & $10 y r s$ & Permanent \\
\hline \multirow[b]{2}{*}{ Age 30} & \multirow{2}{*}{$\$ 0$} & \multirow{2}{*}{$\$ 0$} & \multirow{2}{*}{$\$ 0$} & $\$ 34$ & $\$ 1,272$ \\
\hline & & & & {$[\$ 14+\$ 19]$} & {$[\$ 312+\$ 960]$} \\
\hline \multirow[b]{2}{*}{ Age 35} & $\$ 7$ & $\$ 15$ & $\$ 40$ & $\$ 87$ & $\$ 1,479$ \\
\hline & {$[\$ 3+\$ 4]$} & {$[\$ 6+\$ 9]$} & {$[\$ 18+\$ 22]$} & {$[\$ 40+\$ 47]$} & {$[\$ 364+\$ 1,115]$} \\
\hline \multirow{2}{*}{ Age 40} & $\$ 10$ & $\$ 21$ & $\$ 54$ & $\$ 116$ & $\$ 1,662$ \\
\hline & {$[\$ 5+\$ 5]$} & {$[\$ 10+\$ 11]$} & {$[\$ 26+\$ 28]$} & {$[\$ 58+\$ 58]$} & {$[\$ 404+\$ 1,258]$} \\
\hline \multirow[b]{2}{*}{ Age 45} & $\$ 14$ & $\$ 28$ & $\$ 72$ & $\$ 151$ & $\$ 1,853$ \\
\hline & {$[\$ 7+\$ 7]$} & {$[\$ 14+\$ 14]$} & {$[\$ 38+\$ 34]$} & {$[\$ 83+\$ 68]$} & {$[\$ 443+\$ 1,410]$} \\
\hline
\end{tabular}

Notes: The first (second) figure in squared brackets is the monetized loss of life expectancy (quality) expected from a 24\%-reduction in fish consumption by target consumers aged 30 to 45 at the beginning of the dietary change. The calculation presumes that below the age of $35 \mathrm{CVD}$ risk is negligibly small (Llyod-Jones et al., 2010). 
Figures

Figure 1: Effects of a dietary change in fish consumption lasting from age $a$ through age $t$.

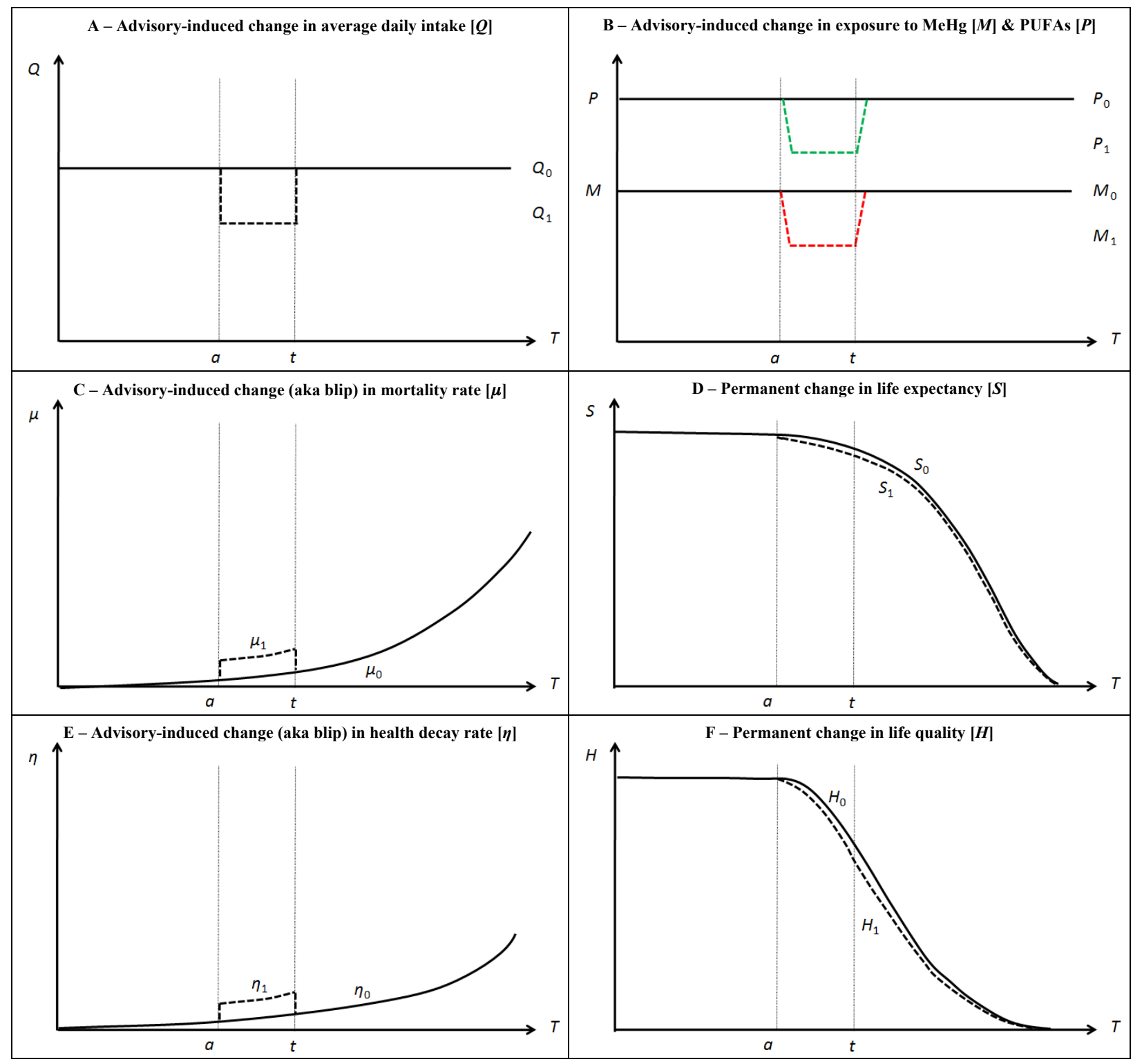


Figure 2: Reported and predicted health quality scores for individuals of different age.

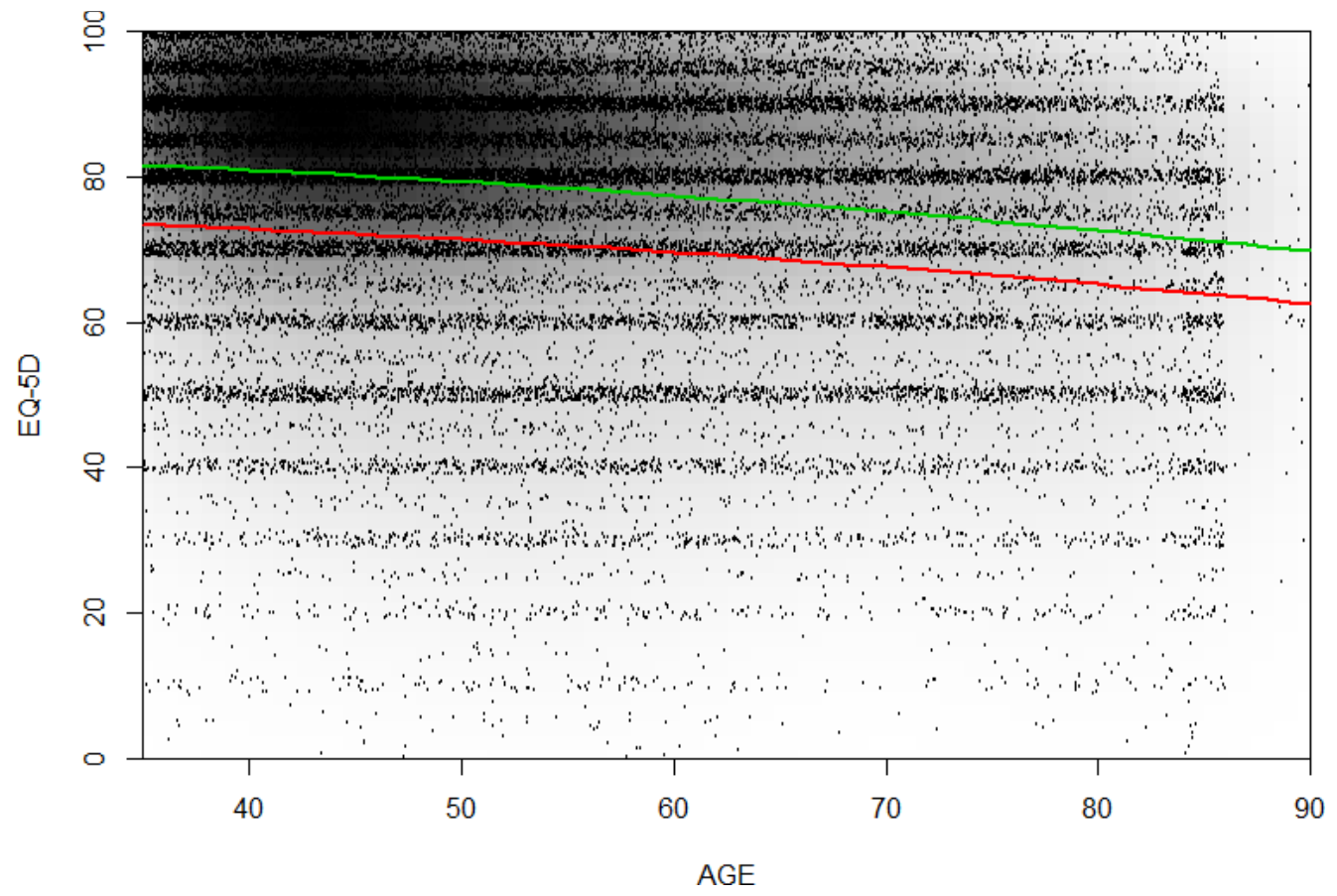

Notes: Figure based on data from the 2000-2003 waves of the Medical Expenditure Survey. The red (green) line shows the predicted decay of health quality over the lifetime for individuals who had (not) suffered a non-fatal CVD event. 


\section{Appendix}

Table A1: Mathematical derivation of advisory-induced changes in life expectancy.

\begin{tabular}{|c|c|c|}
\hline \multirow{13}{*}{ 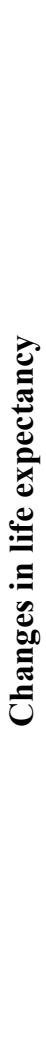 } & Baseline overall mortality at age $t$ & $\mu_{0}(t)=\alpha \exp [\beta t]$ \\
\hline & Baseline heart attack mortality at age $t$ & $\mu_{\mathrm{h}}(t)=\alpha_{\mathrm{h}} e\left[\beta_{\mathrm{h}} t\right]$ \\
\hline & Advisory-induced change in heart attack mortality at age $t$ & $\Delta \mu_{\mathrm{h}}(t)=\mu_{\mathrm{h}}(t) D_{\mathrm{h}}$ \\
\hline & Relative dose-response effect on fatal heart attack risk & $D_{\mathrm{h}}=\psi_{\mathrm{h}} \Delta Q$ \\
\hline & Baseline stroke mortality at age $t$ & $\mu_{\mathrm{s}}(t)=\alpha_{\mathrm{s}} \exp \left[\beta_{\mathrm{s}} t\right]$ \\
\hline & Advisory-induced change in stroke mortality at age $t$ & $\Delta \mu_{\mathrm{s}}(t)=\mu_{\mathrm{s}}(t) D_{\mathrm{s}}$ \\
\hline & Relative dose-response effect on fatal stroke risk & $D_{\mathrm{s}}=\psi_{\mathrm{s}} \Delta Q$ \\
\hline & Overall mortality at age $t$ under dietary change & $\mu_{1}(t)=\mu_{0}(t)+\Delta \mu_{\mathrm{h}}(t)+\Delta \mu_{\mathrm{s}}(t)$ \\
\hline & Advisory-induced change in overall mortality at age $t$ & $\Delta \mu(t)=\mu_{1}(t)-\mu_{0}(t)=\Delta \mu_{\mathrm{h}}(t)+\Delta \mu_{\mathrm{s}}(t)$ \\
\hline & Baseline survival, age $a$ through $t$ & $S_{0}(t, a)=\exp \left[-\int_{a}^{t} \mu_{0}(\tau) d \tau\right]=\exp \left[\frac{\alpha}{\beta}(\exp [\beta a]-\exp [\beta t])\right]$ \\
\hline & Advisory-induced change in survival, age $a$ through $t$ & $\begin{array}{l}\Gamma(t, a)=\int_{a}^{t} \Delta \mu(\tau) d \tau=\int_{a}^{t} \Delta \mu_{\mathrm{h}}(\tau)+\Delta \mu_{\mathrm{s}}(\tau) d \tau= \\
\frac{D_{\mathrm{h}}}{\beta_{\mathrm{h}}}\left[\mu_{\mathrm{h}}(t)-\mu_{\mathrm{h}}(a)\right]+\frac{d_{s} a}{\beta_{\mathrm{s}}}\left[\mu_{\mathrm{s}}(t)-\mu_{\mathrm{s}}(a)\right]\end{array}$ \\
\hline & Survival under dietary change, age $a$ through $t$ & $S_{1}(t, a)=S_{0}(t, a)[1+\Gamma(t, a)]$ \\
\hline & Survival beyond dietary change, age $t$ through death & $S_{1}(\infty, t)=S_{0}(\infty, t)[1+\Gamma(t, a)]$ \\
\hline
\end{tabular}


Table A2: Mathematical derivation of advisory-induced changes in life quality.

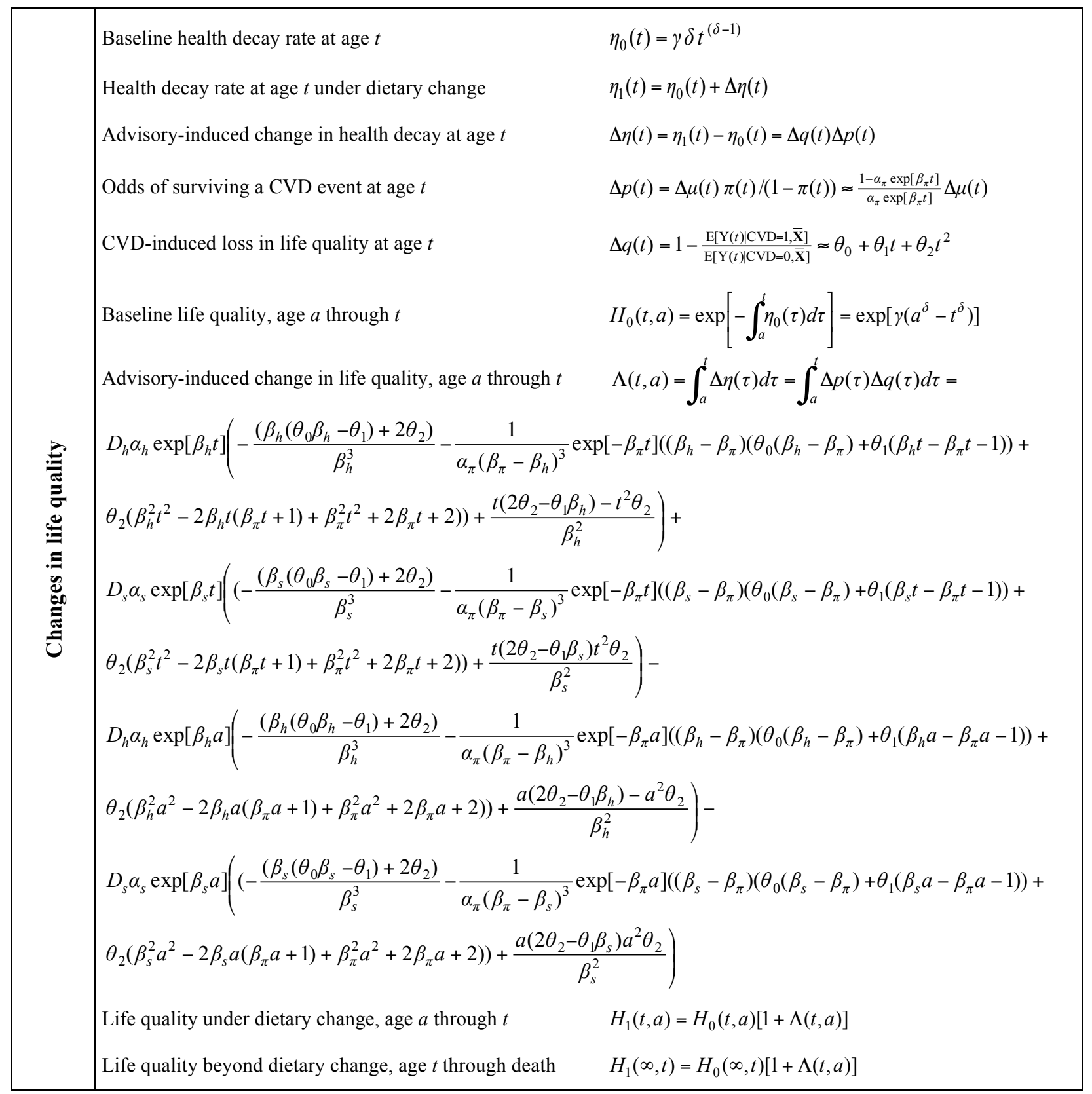


Table A1: Descriptive statistics of the 2000-2003 MEPS data sample $(N=32,222)$.

\begin{tabular}{|c|c|c|c|c|c|}
\hline Variable & Mean & Std. dev. & $5^{\text {th }}$ percentile & Median & $95^{\text {th }}$ percentile \\
\hline Age & 53.95 & 13.67 & 35 & 51 & 80 \\
\hline Female & 0.46 & 0.50 & 0 & 0 & 1 \\
\hline \multicolumn{6}{|l|}{ Race: } \\
\hline Black & 0.13 & & 0 & 0 & 1 \\
\hline White, Hispanic, and Asian Americans & 0.82 & & 0 & 1 & 1 \\
\hline Other races & 0.05 & & 0 & 0 & 0 \\
\hline Body mass index ${ }^{\text {a }}$ & 27.67 & 5.74 & 20.2 & 26.6 & 38.4 \\
\hline Smoking status & 0.22 & 0.41 & 0 & 0 & 1 \\
\hline Depression status & 0.29 & 0.46 & 0 & 0 & 1 \\
\hline Angina status & 0.03 & 018 & 0 & 0 & 0 \\
\hline Diabetes status & 0.10 & 0.30 & 0 & 0 & 1 \\
\hline CVD status & 0.08 & 0.26 & 0 & 0 & 1 \\
\hline \multicolumn{6}{|l|}{ Income class: } \\
\hline Poor $(\mathrm{HHI} \leq 100 \%$ of PL $)$ & 0.12 & & 0 & 0 & 1 \\
\hline Near poor (HHI $100-125 \%$ of PL) & 0.05 & & 0 & 0 & 0 \\
\hline Low income (HHI $126-200 \%$ of PL) & 0.14 & & 0 & 0 & 1 \\
\hline Middle income (HHI $201-400 \%$ of PL) & 0.30 & & 0 & 0 & 1 \\
\hline High income $(\mathrm{HHI}>400 \%$ of PL) & 0.39 & & 0 & 0 & 1 \\
\hline Medical expenditure in the past year & 56.67 & 327.30 & 0 & 0 & 279.90 \\
\hline \multicolumn{6}{|l|}{ Wave: } \\
\hline 2000 & 0.16 & & 0 & 0 & 1 \\
\hline 2001 & 0.27 & & 0 & 0 & 1 \\
\hline 2002 & 0.17 & & 0 & 0 & 1 \\
\hline 2003 & 0.40 & & 0 & 0 & 1 \\
\hline
\end{tabular}

Notes: ${ }^{\text {a }}$ Body mass data for the 2000 wave had to be constructed from data on weight and height. 
Table A2: OLS regression of MEPS health quality scores on controls $(N=32,222)$.

\begin{tabular}{|c|c|c|c|c|c|}
\hline & Coef. & $5 \%-\mathrm{CI}$ & $95 \%-\mathrm{CI}$ & Robust SE & $\operatorname{Pr}(>|t|)$ \\
\hline (Intercept) & 81.257 & 76.565 & 85.950 & 2.346 & 0.000 \\
\hline Age & -0.015 & -0.131 & 0.102 & 0.058 & 0.802 \\
\hline Age : CVD & -0.030 & -0.118 & 0.058 & 0.044 & 0.501 \\
\hline Age : CVD : Depression & 0.162 & 0.028 & 0.295 & 0.067 & 0.016 \\
\hline Age : Depression & -0.068 & -0.103 & -0.034 & 0.017 & 0.000 \\
\hline Age : Male & 0.028 & 0.001 & 0.055 & 0.013 & 0.036 \\
\hline $\mathrm{Age}^{2}$ & -0.002 & -0.003 & -0.001 & 0.001 & 0.002 \\
\hline BMI & 0.369 & 0.125 & 0.612 & 0.122 & 0.003 \\
\hline $\mathrm{BMI}^{2}$ & -0.011 & -0.015 & -0.007 & 0.002 & 0.000 \\
\hline CVD & -5.384 & -11.284 & 0.517 & 2.950 & 0.068 \\
\hline CVD : Depression & -11.817 & -20.728 & -2.906 & 4.455 & 0.008 \\
\hline Angina & -3.762 & -5.057 & -2.466 & 0.648 & 0.000 \\
\hline Depression & -11.404 & -13.287 & -9.521 & 0.942 & 0.000 \\
\hline Diabetes & -5.952 & -6.654 & -5.250 & 0.351 & 0.000 \\
\hline Smoke & -3.410 & -3.865 & -2.955 & 0.228 & 0.000 \\
\hline Medical expenditure & -0.002 & -0.002 & -0.001 & 0.000 & 0.000 \\
\hline Near poor ${ }^{a}$ & 2.852 & 1.716 & 3.989 & 0.568 & 0.000 \\
\hline Low income ${ }^{a}$ & 4.038 & 3.220 & 4.856 & 0.409 & 0.000 \\
\hline Middle income ${ }^{a}$ & 6.620 & 5.901 & 7.340 & 0.360 & 0.000 \\
\hline High income $^{a}$ & 8.507 & 7.802 & 9.211 & 0.352 & 0.000 \\
\hline Male & -1.824 & -3.260 & -0.387 & 0.718 & 0.011 \\
\hline Black $^{\text {b }}$ & -0.244 & -0.814 & 0.326 & 0.285 & 0.392 \\
\hline Other races ${ }^{b}$ & -2.620 & -3.446 & -1.794 & 0.413 & 0.000 \\
\hline Wave 2001 & 1.799 & 1.246 & 2.353 & 0.277 & 0.000 \\
\hline Wave 2002 & 1.886 & 1.273 & 2.499 & 0.307 & 0.000 \\
\hline Wave 2003 & 2.030 & 1.497 & 2.562 & 0.266 & 0.000 \\
\hline $\mathrm{R}^{2}$ & 0.320 & & & & \\
\hline \multicolumn{6}{|c|}{ Residual SE: 15.39 on 32196 degrees of freedom } \\
\hline \multicolumn{6}{|c|}{ F-statistic: $\quad 607$ on 25 and $32196 \mathrm{DF}, \mathrm{p}$-value: $<2.2 \mathrm{e}-16$} \\
\hline
\end{tabular}

Notes: ${ }^{a}$ Baseline is poverty line; ${ }^{b}$ baseline are White, Hispanic, or Asian Americans. 


\section{References}

Aldy J.E., Viscusi W.K., 2008. Adjusting the value of a statistical life for age and cohort effects. Review of Economics and Statistics 90, 573-581.

Arias E. 2011. United States Life Tables, 2007. National Vital Statistics Reports 59(9). National Center for Health Statistics: Hyattsville, MD.

Arthur W.B., 1981. The Economics of Risks to Life. American Economic Review 71, 54-64.

Axelrad D.A., et al., 2007. Dose-Response Relationship of Prenatal Mercury Exposure and IQ: An Integrative Analysis of Epidemiological Data. Environmental Health Perspectives 115, 609-615.

Cohen J.T., et al., 2005a. A Quantitative Analysis of Prenatal Intake of n-3 Polyunsaturated Fatty Acids and Cognitive Development. American Journal of Preventive Medicine 29, 366-374.

Cohen J.T., et al., 2005b. A Quantitative Risk-Benefit Analysis of Changes in Population Fish Consumption. American Journal of Preventive Medicine 29, 325-334.

Cropper M.L., Sussman F.G., 1990. Valuing Future Risks to Life. Journal of Environmental Economics and Management 19, 160-174.

EuroQol Group, 1990. EuroQol-a new facility for the measurement of health-related quality of life. Health Policy 16, 199-208.

Garber A.M., Phelps C.E., 1997. Economic foundations of cost-effectiveness analysis. Journal of Health Economics 16, 1-31.

Hammitt J.K., 2002. QALYs versus WTP. Risk Analysis 22, 985-1001.

Hammitt J.K., 2004. Economic implications of hormesis. Human and Experimental Toxicology 23, 267-278.

Hammitt J.K., 2007. Valuing Changes in Mortality Risk: Lives Saved vs. Life Years Saved. Review of Environmental Economics and Policy 1, 228-240.

Heron M., et al. 2009. Deaths: Final Data for 2006. National Vital Statistics Reports 57(14). National Center for Health Statistics: Hyattsville, MD.

Johannesson M., Johansson P.O., Löfgren K.G., 1997. On the Value of Changes in Life Expectancy: Blips Versus Parametric Changes. Journal of Risk and Uncertainty 15, 221-239.

Johansson P.O., 2001. Is there a meaningful definition of the value of a statistical life? Journal of Health Economics 20, 131-139.

Johansson P.O., 2002. On the definition and age dependency of the value of a statistical life. Journal of Risk and Uncertainty 25, 251-263.

Lee J.H., et al., 2009. Omega-3 fatty acids: cardiovascular benefits, sources and sustainability. Nature Review Cardiology 6, 753-758. 
Leung S.F., 1994. Uncertain Lifetime, The Theory of the Consumer, and the Life Cycle Hypothesis. Econometrica 62, 1233-1239.

Lloyd-Jones D., et al., 2010. Heart Disease and Stroke Statistics-2010 Update A Report From the American Heart Association. Circulation 121, E46-E215.

Mozaffarian D., Rimm E.B., 2006. Fish Intake, Contaminants, and Human Health. Journal of the American Medical Association 18, 1885-1896.

Murphy K.M., Topel R.H., 2006. The value of health and longevity. Journal of Political Economy 114, 871-904.

NRC, 2000. Toxicological Effects of Methylmercury. Committee on the Toxicological Effects of Methylmercury, National Research Council. National Academy Press, Washington, DC.

Oken E., et al., 2005. Maternal fish consumption, hair mercury, and infant cognition in a US cohort. Environmental Health Perspectives 113, 1376-1380.

Rheinberger C.M., Hammitt J.K., 2012. Risk Trade-Offs in Fish Consumption: A Public Health Perspective. Environmental Science and Technology 46, 12337-12346.

Roman H.A., et al., 2011. Evaluation of the Cardiovascular Effects of Methylmercury Exposures: Current Evidence Supports Development of a Dose-Response Function for Regulatory Benefits Analysis. Environmental Health Perspectives 119, 607-614.

Rosen S., 1988. The Value of Changes in Life Expectancy. Journal of Risk and Uncertainty 1, 285-304.

Shepard D.S., Zeckhauser R.J., 1984. Survival versus Consumption. Management Science 30, 423-439.

Shimshack J.P., Ward M.B., 2010. Mercury advisories and household health trade-offs. Journal of Health Economics 29, 674-685.

Van Houtven G., et al., 2006. Valuing avoided morbidity using meta-regression analysis: what can health status measures and QALYs tell us about WTP? Health Economics 15, 775-795.

Yaari M.E., 1965. Uncertain Lifetime, Life Insurance and the Theory of the Consumer. Review of Economic Studies 32, 137-150. 